\title{
Predictors of Failure in Medical Students
}

\author{
Jong Park', Myung Geun Kang' ${ }^{1}$, So Yeon Ryu', Jae Won You ${ }^{2}$ and Kyung Rye Moon ${ }^{3}$ \\ Departments of ${ }^{1}$ Preventive Medicine, ${ }^{2}$ Orthopaedic Surgery, ${ }^{3}$ Pediatrics, College of Medicine, Chosun University, \\ Gwangju, Korea
}

\section{의과대학생의 유급 발생 예측요인 분석: 일개 의과대학 자료를 중심으로}

조선대학교 의과대학 ${ }^{1}$ 예방의학교실, ${ }^{2}$ 정형외과학교실, ${ }^{3}$ 소아과학교실

박 종 $^{1}$, 강명근 $^{1}$, 류소연 ${ }^{1}$, 유재원 $^{2}$, 문경래 $^{3}$

Purpose: This study aimed to identify the predictors of failure in medical students.

Methods: We conducted a 10-year follow-up survey of 231 medical students. The students' general characteristics, study-related factors, health-related behavior, and self-perceived health were examined using questionnaires that were given late in the first year of a premedical course. We evaluated the failure incidence of students using school records from the second year of a premedical course to the fourth year of medical school. The statistical analyses that were used were $\chi^{2}$-test, student t-test, and multiple logistic regression analysis.

Results: Sixty-five students experienced failure. Thirty-seven (56.9\%) had 1 failure, $11(16.9 \%)$ had 2 failures, $8(12.3 \%)$ had 3 failures, $4(6.2 \%)$ had 4 failures, and $5(7.7 \%)$ had 5 failures. From the results of multiple logistic regression, the rates of failure were significantly higher for those whose grade point average (GPA) in the first year of a premedical course was below 2.5 (Relative Risk $[R R]=6.52,95 \%$ Confidence Interval $[\mathrm{Cl}]$ : 1.42 29.8), who smoked more than 1 pack of cigarettes per day $(\mathrm{RR}=7.37,95 \% \mathrm{Cl}: 1.23 \sim 44.07)$, who drank more $(\mathrm{RR}=1.16,95 \% \mathrm{Cl}: 1.02 \sim 1.33)$, and exercised less $(\mathrm{RR}=0.997,95 \%$ $\mathrm{Cl}: 0.995 \sim 0.999)$.

Conclusion: It was demonstrated that the incidence of failure in medical students was reflected in their academic records in the first year of a premedical course and by unhealthy lifestyles. This study suggests that students who have poor academic marks and unhealthy lifestyles in the first year of a premedical course should be properly guided to reduce the incidence of failure.

Key Words: Predictors, Failure incidence, Medical students

Received: November 7, 2008 - Accepted: February 18, 2009

Corresponding Author: Jong Park

Department of Preventive Medicine, College of Medicine, Chosun University, 375,

Seosuk-dong, Dong-gu, Gwangju 501-759, Korea

TEL) 062-230-6482 FAX) 062-225-8293 E-mail) jpark@chosun.ac.kr

* A part of this paper was presented at the 17th Scientific Meeting of the Korean Society of Medical Education in May, 2005.
Korean J Med Educ 2009 Jun; 21(2): 143-151. doi: 10.3946/kjme.2009.21.2.143.

(C) The Korean Society of Medical Education. All rights reserved. 


\section{서론}

의과대학에서는 학생의 학업성취도를 평가한 후 부 진한 학생에 대하여 학년제로 진급여부를 결정하여 해 당 학년의 전 과목을 다시 이수해야 하는 유급제도를 적용하고 있다. 이는 우리나라의 모든 의과대학에서 시 행하고 있으며 거의 대부분의 대학에서 한 과목에서만 $\mathrm{F}$ 학점을 취득하여도 유급이 되는 등 그 규정이 매우 엄 격하며 적용 또한 철저히 이루어지고 있다[1].

이러한 유급제도는 그 필요성을 인정하면서도 다양 한 문제점을 유발할 수 있다. 먼저 유급으로 인한 자신 감의 결여와 심리적 위축감 등으로 인한 자아 존중감의 저하, 의과대학 내의 동기, 친구, 선후배뿐만 아니라 이 성친구나 가족과의 관계 설정의 변화를 초래할 수 있고, 유급으로 인한 학생으로서의 제한된 입지로 인해 심리 적 부담을 가질 수 있어 학생 개인의 삶의 질에 심각한 영향을 초래할 수 있어[2] 유급 학생에 대한 체계적인 관리와 유급규정에 대한 적절한 개선의 필요성이 대두 되고 있다.

1995년도 우리나라 전체 의과대학생의 유급 경험률 을 보면, 1995년 입학정원을 근거로 한 전국의 의과대 학생 11,520 명 중[3] 약 $16.1 \%$ 인 1,850 여 명으로 추정 되었으며[1], 1997년도 한 대학 의예과 및 의학과 유급 학생 수는 입학정원을 기준으로 한 전체 재학생 870여 명의 $11.1 \%$ 에 해당하는 97명이었다[4]. 2002년도 우리 나라 41 개 의과대학의 유급자수를 보면 의예과에서 153 명, 의학과에서 771 명으로 전체적으로는 924 명이었 고, 2003년도에는 의예과에서 134명, 의학과에서 761 명으로 895명이었다[5]. 외국의 경우를 보면, 한 의과대 학 전체 입학자의 $11.3 \%$ 가 학업부진으로 졸업을 하지 못한 것으로 나타났다[6].

의과 대학생의 중도 탈락과 관련된 요인으로는 성별 특히 남학생, 연령[7,8], 수업의 출석, 수업에 대한 준비 [9], 학생의 의지, 그리고 정신적, 감정적 동요 등의 개 인적 특성이 중요하게 작용하는 것으로 조사되었다 [10,11]. 또한 낮은 사회경제적 수준, 가족 내의 문제
[12] 등의 외부적 요인도 관련이 있는 것으로 보고되었 다.

우리나라에서도 많은 의과대학생들이 유급을 경험하 고 있으나 그 발생 요인에 대한 연구는 지금까지 이루 어진 적이 없다. 이에 본 연구는 한 대학 의과대학생을 대상으로 10 년 동안의 추적 조사를 실시하고 어떤 특성 들이 유급발생과 관련이 있는지를 파악하여 이 요인들 의 관리체계를 구축하는 데 필요한 기본 자료를 제공함 으로써 유급률을 낮추는 데 기여하고자 시도되었다.

\section{대상 및 방법}

\section{1. 연구 대상}

한 개 의과대학 의예과에 1995년에 입학한 학생 145 명, 1996년에 입학한 145 명 등 총 290명을 대상으로 의 예과 1학년 말에 설문조사를 실시하였다. 이들을 대상 으로 의예과 1학년 말에 유급 여부를 조사한 결과 270 명이 유급 경험이 없었다. 이들 중 설문조사 자료가 불 충실했던 39명을 제외하고 의학과 4학년까지 반복 유급 으로 인한 최장 10 년 동안의 학적부 추적이 가능했던 231 명을 최종 분석대상으로 하였다.

\section{2. 자료수집방법}

설문조사의 내용으로는 유급과 관련이 있을 것으로 판단되는 다양한 특성을 파악하였다. 일반적 특성으로 학생의 나이, 성별 등을 조사하였다. 학업 관련 특성으 로는 의예과 1학년 말에 학생이 취득한 전체평균평점 (grade point average, GPA)을 학적부를 통하여 파악 하였다. 규칙적으로 공부를 하는지의 여부는 학교나 집 에서 스스로 시간을 정해 놓고 규칙적으로 공부를 하고 있는지를 파악하였으며, 공부 때문에 바쁘다고 느껴본 적이 얼마나 되는지를 '대부분의 학생보다 덜하다', '대 부분의 사람과 같다', '대부분의 학생보다 더 많다'로 측 정하였다. 건강 관련 특성에서 흡연정도는 흡연 유무를 질문 후 흡연을 하고 있다고 응답한 학생에 대해 하루 
흡연량을 조사하였다. 음주량은 일주일에 마시는 술의 양을 잔으로 표시하게 하였다. 하루 평균 수면시간을 조사하였고, 일주일 동안의 운동 시간은 등산, 달리기, 수영 등의 종목에 대해 일주일 동안 운동한 날수와 1 회 운동시간을 분으로 질문하여 계산하였다. 신체적 건강 인식은 '건강하다', '병은 없지만 건강한 편은 아니다', '무슨 병이 있는 것 같다', '질병이 있다'의 4개 범주로 측정하였다. 정신적 건강인식은 정신적인 건강에 대해 '나쁘다', ‘보통이다', '좋다', '아주 좋다'의 4개 범주로 측 정하였다.

유급 관련 변수는 231 명의 연구대상자에 대해 의예과 2 학년부터 의학과 4학년까지 각 학년도의 학적부를 추 적하여 유급 여부, 유급횟수를 조사하였다. 학생에 따라 서는 의학과 4 학년까지의 반복 유급으로 인해 최장 10 년 동안의 학적부를 추적 조사하였다.

\section{3. 분석방법}

분석을 위해 변수의 범주를 재분류하였다. 공부 때문 에 바쁘다고 느껴본 적이 얼마나 되는지는 '대부분의 학 생보다 덜하다', '대부분의 사람과 같다'고 응답한 군은 '바쁘지 않은 군'으로, '대부분의 학생보다 더 많다’로 응 답한 군은 '바쁜 군'으로 재분류하였다. 흡연량은 비흡 연, 반 갑 이하, 한 갑 이하, 한 갑 초과군으로 재분류 하였고, 정신적 건강인식은 정신적인 건강에 대해 "아주 좋다로 응답한 군이 너무 적어 나쁨, 보통, 좋음+아주 좋음의 세 군으로 재분류하였다.

분석은 유급 관련 특성인 횟수, 학년별 유급자수 등 의 빈도를 파악하였다. 일반적 특성, 학업관련 변수, 건 강행위, 신체적, 정신적 건강인식 특성 등을 독립 변수 로 하고, 유급발생 여부를 종속 변수로 하여 $\chi^{2}$-test, student t-test를 시행하여 관련성을 파악하였다. 최종 적으로 단순 분석에서 경계역 이상의 유의한 관련을 갖 는 변수를 독립변수로 하고 유급발생 여부를 종속변수 로 하여 다변량 로지스틱 회귀분석(multiple logistic regression analysis)을 시행하고 비교위험도와 $95 \%$ 신 뢰구간을 구하였다.

\section{결과}

연구대상자 231 명 중 재학 기간 동안 유급경험자는 65 명으로 유급 경험률은 $28.1 \%$ 였고 유급 횟수는 1회가 37명(56.9\%), 2회가 11명(16.9\%), 3회가 8명(12.3\%), 4 회가 4명(6.2\%), 5회가 5명(7.7\%)이었다(Fig. 1). 학년 별로 유급자수를 중복을 허용하여 살펴보면 의예과 2학 년 6명, 의학과 1 학년 71 명, 의학과 2학년 22명, 의학과 3학년 10명이었다(Fig. 2).

일반적 특성과 유급 발생과의 관련성을 보면 남자에 서 유급발생률은 $31.7 \%$ (60명), 여자에서는 $11.9 \%$ (5 명)로 남자에서 유의하게 높았다 $(\mathrm{p}<0.05)$. 나이가 많아 질수록 유급발생이 높았으나 통계적으로 유의한 차이 를 보이지 않았다(Table 1).

Fig. 1. Number of Failure Experiences

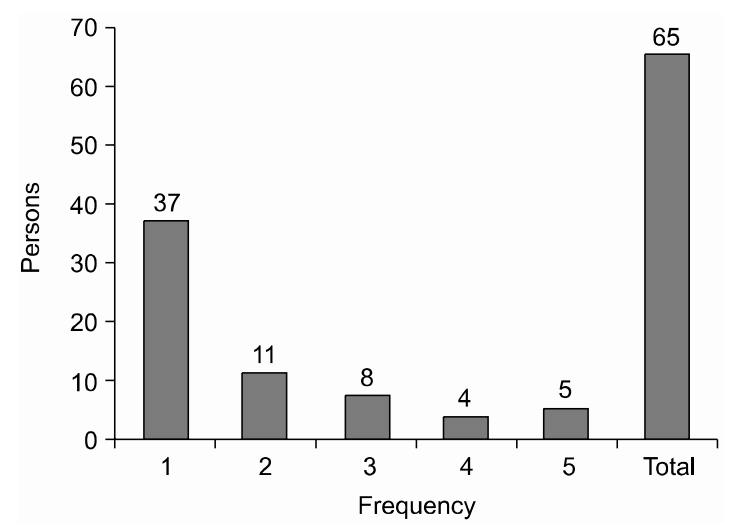

Fig. 2. Number of Failure Experiences by Grade (Duplication Allowed)

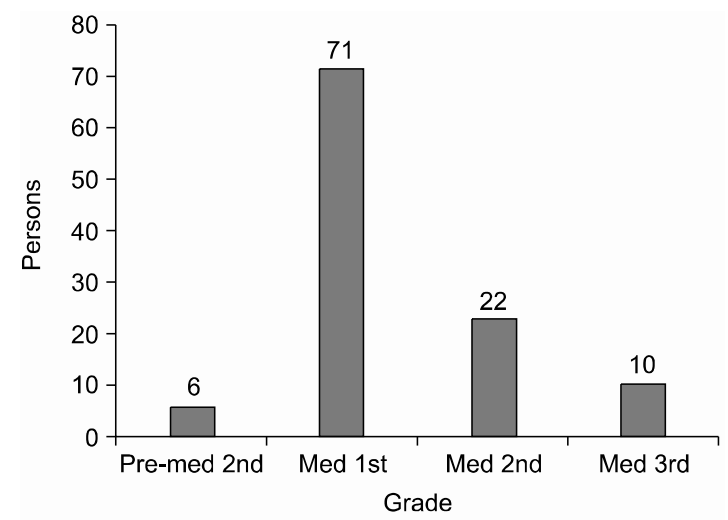


Table 1. Association between General Characteristics of Subjects and Failure Incidence

\begin{tabular}{ccrrr}
\hline Variables & Class & Failure $1+$ ) & \multicolumn{1}{c}{ Failure (-) } & \multicolumn{1}{c}{$p$} \\
\hline Age lyrs) & 19 & $20(23.3)$ & $66(76.7)$ & 0.414 \\
& 20 & $25(28.7)$ & $62(71.3)$ & \\
& 21 & $9(28.1)$ & $23(71.9)$ & \\
22 & $4(36.4)$ & $7(63.3)$ & \\
& 23 & $7(46.7)$ & $8(53.3)$ & \\
& Male & $60(31.7)$ & $129(68.3)$ & 0.017 \\
& Female & $5(11.9)$ & $37(88.1)$ & \\
\hline
\end{tabular}

Table 2. Association between Study-Related Factors and Failure Incidence

\begin{tabular}{ccccc}
\hline Variables & Class & Failure $(+)$ & Failure $(-)$ & $p$ \\
\hline Too busy to study & Yes & $14(19.2)$ & $59(80.8)$ & 0.054 \\
Regular studying & No & $51(32.5)$ & $106(67.5)$ & \\
& Yes & $26(22.4)$ & $90(77.6)$ & 0.066 \\
Grade point average (GPA) & No & $39(34.2)$ & $75(65.8)$ & \\
& $3.50 \sim$ & $3(7.5)$ & $37(92.5)$ & 0.000 \\
& $3.00 \sim 3.49$ & $17(20.5)$ & $66(79.5)$ & \\
& $2.50 \sim 2.99$ & $26(36.6)$ & $45(63.4)$ & \\
& $\sim 2.49$ & $19(51.4)$ & $18(48.6)$ & \\
\hline
\end{tabular}

Table 3. Association between Health-Related Behaviors and Failure Incidence

\begin{tabular}{ccccc}
\hline Variables & Class & Failure $(+)$ & Failure (-) & $p$ \\
\hline Amount of smoking & No smoking & $33(19.8)$ & $134(80.2)$ & 0.000 \\
& $\sim$ half pack & $10(38.5)$ & $16(61.5)$ & \\
& $\sim$ one pack & $15(51.7)$ & $14(48.3)$ & \\
& Over one pack & $7(77.8)$ & $2(22.2)$ & \\
& $1.37 \pm 0.65$ & $0.33 \pm 1.48$ & 0.011 \\
$\begin{array}{c}\text { Amount of drinking } \\
\text { (glasses/week, M } \pm \text { SD) }\end{array}$ & $7.14 \pm 1.17$ & $7.13 \pm 1.30$ & 0.974 \\
$\begin{array}{c}\text { Average hours of sleep } \\
\text { (hrs/day, M } \pm \text { SD) }\end{array}$ & & & \\
Exercise time $(\mathrm{min} /$ week, $\mathrm{M} \pm$ SD) & $125.34 \pm 154.60$ & $212.83 \pm 264.38$ & 0.002 \\
\hline
\end{tabular}

SD: Standard deviation.

학업특성과 유급 발생과의 관련성을 보면 공부 때문 에 바쁘다고 인식하고 있는 군의 유급발생률은 $19.2 \%$, 그렇지 않은 군은 $32.5 \%$ 로 그리고 규칙적으로 공부를 한다고 응답한 군은 $22.4 \%$, 그렇지 않은 군은 $34.2 \%$ 로 경계역 수준의 유의한 차이를 보였다 $(\mathrm{p}<0.1)$. 의예과 1
학년 동안의 GPA가 2.5 미만인 군의 유급 발생률은 $51.4 \%, 2.5$ 에서 3.0 미만인 군은 $36.6 \%, 3.0$ 에서 3.5 미 만군은 $20.5 \%$, 그리고 3.5 이상군은 $7.5 \%$ 로 유의한 차 이를 보였다 $\mathrm{p}<0.001)$ (Table 2).

건강행위와 유급발생과의 관련성을 보면 비흡연자의 
박 종 외: 의과대학생의 유급발생 예측요인 분석: 일개 의과대학 자료를 중심으로

유급 발생률은 $19.8 \%$, 반 갑 이하 흡연자는 $38.5 \%$, 한 갑 이하는 $51.7 \%$, 한 갑 초과자는 $77.8 \%$ 로 흡연량에 따 라 유의한 차이를 보였다 $(\mathrm{p}<0.001)$. 주당 평균 음주량 에 있어서도 유급자는 $1.37 \pm 0.65$ 잔, 비유급자는 0.33 \pm 1.48 잔으로 유급자에서 유의하게 많았으며 $(\mathrm{p}<0.05)$, 운동시간도 유급자는 $125.34 \pm 154.60$ 분, 비유급자는 $212.83 \pm 264.38$ 분으로 유급자에서 유의하게 적었다 $(\mathrm{p}<0.01)$ (Table 3). 그러나 수면시간, 신체적 정신적 건강인식에 따라서는 두 군 간에 유의한 차이를 보이지
않았다(Table 3, 4).

다변량 로지스틱 회귀분석 결과 의예과 1 학년의 GPA 3.5 이상군에 비해 2.5 미만인 군에서(Relative Risk $[\mathrm{RR}]=6.52$, 95\% Confidence Interval [CI]: 1.42 29.8), 비흡연군에 비해 하루 흡연량이 한 갑 초 과군에서( $\mathrm{RR}=7.37,95 \% \mathrm{CI}: 1.23 \sim 44.07)$, 음주량이 많을수록(RR=1.16, 95\% CI: 1.02 1.33) 유급발생이 유의하게 높았으며, 운동량이 많을수록(RR=0.997, 95\% CI: 0.995 0.999) 유의하게 낮았다(Table 5).

Table 4. Association between Self-Perceived Health and Failure Incidence

\begin{tabular}{clrrc}
\hline \multicolumn{1}{c}{ Variables } & \multicolumn{1}{c}{ Class } & Failure $(+)$ & Failure (-) & $p$ \\
\hline Physical health & Healthy & $31(29.0)$ & $76(71.0)$ & 0.497 \\
& No disease but unhealthy & $30(30.3)$ & $69(69.7)$ & \\
& Possibly ill & $3(20.2)$ & $12(80.0)$ & \\
& With disease & $1(10.0)$ & $9(90.0)$ & \\
Mental health & Bad & $44(33.6)$ & $87(66.4)$ & 0.108 \\
& Moderate & $15(20.8)$ & $57(79.2)$ & \\
& Good & $6(21.4)$ & $22(78.6)$ & \\
\hline
\end{tabular}

Table 5. Multiple Logistic Regression Analysis for Failure Incidence

\begin{tabular}{llll}
\hline Variables & Class & b & RR (95\% CI) \\
\hline Grade point average (GPA) & $3.5 \sim$ & & 1.000 \\
& $3.0 \sim 3.49$ & 0.849 & $2.337(0.580 \sim 9.248)$ \\
& $2.5 \sim 2.99$ & 1.404 & $4.070(0.998 \sim 16.604)$ \\
Amount of smoking & $\sim 2.49$ & 1.875 & $6.522(1.426 \sim 29.823)$ \\
& No smoking & & 1.000 \\
Amount of drinking (glass) & $\sim$ half pack & 0.521 & $1.684(0.645 \sim 4.394)$ \\
Exercise time (min/week) & $\sim$ one pack & 0.760 & $2.138(0.812 \sim 5.630)$ \\
Sex & Over one pack & 1.998 & $7.371(1.233 \sim 44.078)$ \\
& & 0.153 & $1.169(1.017 \sim 1.336)$ \\
Too busy to study & Female & -0.003 & $0.997(0.995 \sim 0.999)$ \\
& Male & & 1.000 \\
Regular studying & Yes & 0.206 & $1.229(0.401 \sim 3.766)$ \\
& No & & 1.000 \\
\hline
\end{tabular}

RR: Relative risk, Cl: Confidence interval. 


\section{고찰}

의예과 2 학년부터 의학과 4학년까지 재학기간 동안 추적조사가 이루어졌던 연구대상자 231명 중 유급경험 자는 65 명으로 반복 유급으로 인한 10년 동안의 유급 발생률은 $28.1 \%$ 였다. 이러한 결과는 10 년 동안 의과대 학에 입학한 학생 443 명을 대상으로 학업과 관련된 이 유로 제때에 졸업을 하지 못한 비율인 $11.3 \%[6]$ 에 비해 높았으며, 1995년도 우리나라의 의예과생을 포함한 의 과대학의 추정 유급 경험률인 $16.1 \%[1]$ 보다도 높았다. 하지만 이 두 연구는 단면조사로서 본 연구의 유급 발 생을 추정한 추적조사와는 차이가 있어 직접적인 비교 가 어려운 점이 고려되어야 할 것으로 생각한다. 2003 년과 2004년의 우리나라 의과대학에서 유급을 경험한 학생 수는 924명, 824명으로 보고되어[5], 매년 약 900 여 명의 많은 학생이 유급을 경험하는 것으로 추정된다. 이들이 겪는 사회경제적, 정신심리적 그리고 학업상의 문제뿐만 아니라 학부모들이 겪는 고통도 상당할 것으 로 예상되어 유급 제도 개선과 학생 관리에 대한 적절 한 보완과 개선이 필요할 것으로 생각한다.

유급 경험자의 내용을 살펴보면 65명 중 2회 이상이 28 명 (42.1\%)으로 거의 절반 정도를 차지하였고, 특히 9 명(13.8\%)은 4회 이상을 보여 한번 유급을 경험한 학생 이 반복적으로 경험하고 있음을 잘 보여주고 있다. 학 년별로 유급자수를 중복을 허용하여 살펴본 결과 의학 과 1학년 71명, 의학과 2학년 22명으로 이들 2개 학년 에서 대부분을 차지하였고 특히 의학과 1 학년은 타 학 년에 비해 많았다. 이는 대부분의 유급 경험자들이 의 예과에 비해 과도하게 많아진 학업량과 치열한 경쟁에 잘 적응하지 못했기 때문으로 판단된다[2]. 따라서 의과 대학생의 유급률을 낮추기 위해서는 의학과 1 학년과 의 학과 2학년 시기에 과도한 학습 부담과 경쟁으로 인한 압박감을 덜어주기 위한 적절한 관리와 지도가 필요할 것으로 생각한다.

의예과 1학년의 성적은 유급 발생을 예측하는 중요한 요인임이 판명되었다. 본 연구결과에 의하면 의예과 1
학년의 GPA가 나쁠수록 유급발생이 증가하는 양-반응 결과를 보였다. 특히 평균평점이 2.50 미만인 군은 3.50 이상인 군에 비해 6.52 배 유의하게 높은 유급발생을 보 여 강력한 예측요인임을 알 수 있었다. 아직까지 의과 대학생을 대상으로 하여 유급과 성적과의 관련성을 명 백하게 밝힌 연구는 없었으나 Arulampalam et al.[9] 은 수업의 출석이 저조하고 수업 준비 등이 부족한 학 생에서 중도 탈락이 유의하게 높았음을 보고하였다. 본 연구에서도 수업관련 요인으로 선정한 공부 때문에 바 쁜지의 여부, 규칙적으로 공부를 하는지의 여부 등이 단순분석 상에서는 유의한 관련을 보여 기존의 연구와 일치하는 결과를 보였으나 다른 요인을 통제한 후에는 단지 의예과 1 학년의 GPA만이 선택되었다. 따라서 의 예과 1학년 시기에 성적이 좋지 않은 학생들에 대한 집 중적인 관리와 지도는 유급률을 낮추는 데 중요한 역할 을 할 것으로 판단된다.

흡연은 본 연구에서 유급 발생에 가장 강력한 관련성 을 보이는 변수로 확인되었다. 하루 한 갑 초과 흡연자 는 비흡연자에 비해 7.37배 유의하게 높았고, 흡연량이 증가할수록 증가하여 양-반응 관계를 보였다. 지금까지 의과대학생을 대상으로 흡연과 유급 발생과의 관련성 을 밝힌 연구가 미비하여 직접적인 비교는 할 수 없었 으나 청소년에서 흡연이 학업의 실패와 유의한 관련이 있다는 연구[13]와는 일치하는 결과를 보였다.

의과대학생의 유급 예측 요인으로 음주가 유의한 관 련을 보여 음주량이 많을수록 유급 발생률이 유의하게 높아진 것도 의미 있는 결과라 생각한다. 이는 Jeong [14]의 일부 대학생을 대상으로 한 연구에서 문제성 음 주가 낮은 학업성적과 관련이 있다는 연구보고와 일치 하였다. 운동시간이 많을수록 유급 발생이 유의하게 낮 은 것은 운동의 직접적인 요인이라기보다는 본 연구 자 료의 세부적인 상관분석 결과 운동량이 많을수록 흡연 량과 음주량이 줄어드는 역상관 관계를 보여 운동과 흡 연, 음주 등의 생활습관이 복합적으로 작용했기 때문이 라고 판단하는 것이 적절하다고 생각한다.

본 연구의 제한점으로는 기존의 연구[9,10,11,12]에 서 유급과 관련이 있었던 것으로 보고된 입학성적, 수 
업의 출석, 정신적, 감정적 동요 등의 개인적 특성, 사회 경제적 수준, 가족 내의 문제, 그리고 새로이 대두되고 있는 인터넷 사용 등의 다양한 변수들과 유급과의 관련 성에 대해 밝히지 못했다는 점이다. 향후의 연구에서는 이들 변수들에 대한 적절한 조사가 이루어져 보완이 된 다면 유급의 예측 요인들을 더 명확하게 규명할 수 있 을 것으로 판단한다.

본 연구는 이러한 제한점에도 불구하고 2 개 학년도의 의예과 1 학년 학생을 대상으로 10 년 동안의 장기적인 추적 조사를 통하여 의과대학 교육의 중요한 문제 중 하나인 유급 발생에 학업 성적과 흡연, 음주 등의 생활 습관이 유의한 관련이 있음을 우리나라에서 처음으로 규명하였다는 데 의의가 있다고 생각하며, 이를 바탕으 로 유급률을 낮추고 유급 학생들의 관리를 위한 적절한 대책이 강구되어야 할 것으로 판단된다.

\section{ACKNOWLEDGEMENTS}

This study was supported by research funds from Chosun University, 2008.

\section{REFERENCES}

1. The Korean Council of Deans of Medical College. The current educational status of college of medicine. no.9. (1996-1997). Seoul, Korea: Gyechukmunwhasa; 1996.

2. Kim SH, Jeon WT. The failure experiences of medical school students: a qualitative study. Korean J Med Educ 2008; 20: 351-362.

3. Kim CY, Kim SM, Seo JD, Earm YE, Ahn YO, Kim $\mathrm{S}$, et al. A survey of students' satisfaction on medical education. Korean J Med Educ 1996; 8: 169-188.

4. Park J, Park SK, Park SH, Do NY, Song CH, Lee SL, et al. The pilot study for the improvement of the flunk system in Chosun University Medical School. Med J Chosun Univ 1998; 23: 85-94.

5. The Korean Council of Deans of Medical College. The current educational status of college of medicine. no.13. (2004-2005). Seoul, Korea: Aram; 2004.

6. Lazin R, Neumann L. Student characteristics as predictors of drop-out from medical school: admissions to Beer-Sheva over a decade. Med Educ 1991; 25: 396-404.

7. James D, Chilvers C. Academic and non-academic predictors of success on the Nottingham undergraduate medical course 1970-1995. Med Educ 2001; 35: 1056-1064.

8. Arulampalam W, Naylor R, Smith J. Factors affecting the probability of first year medical student dropout in the UK: a logistic analysis for the intake cohorts of 1980-92. Med Educ 2004; 38: 492-503.

9. Arulampalam W, Naylor RA, Smith JP. Dropping out of medical school in the UK: explaining the changes over ten years. Med Educ 2007; 41: 385-394.

10. Thomas CB. What becomes of medical students: the dark side. Johns Hopkins Med J 1976; 138: 185-195.

11. Finn JD, Rock DA. Academic success among students at risk for school failure. J Appl Psychol 1997; 82: 221-234.

12. Biggs JS, Najman JM, Schulz EB, Williams G. Parental problems influencing the academic achievement of medical students: a prospective study. Med Educ 1991; 25: 374-382.

13. Collins BN, Wileyto EP, Murphy MF, Munafò MR. Adolescent environmental tobacco smoke exposure predicts academic achievement test failure. J Adolesc Health 2007; 41: 363-370.

14. Jeong WC. The actural condition and the impact of psychosocial factors on problem drinking among the college students. Korean J Soc Welfare 2006; 58: 347-372. 
Appendix 1. 설문지

이 설문지는 의예과 학생을 대상으로 장기적인 추적관찰을 목적으로 만들어졌으며, 현재의 건강수준과 건강 활동의 정도를 파악하고자 합니다. 귀하가 대답한 내용은 통계적인 분석 자료로만 사용되며 다른 목적으로는 이용되지 않습니다. 따라서 응답한 내용에 대해서는 비밀이 철저히 보장될 것입니다. 한 문항도 빠뜨리지 말고 솔직하고 성실하게 응답해 주기를 부탁합니다.

당신은 담배를 피운 적이 있습니까?
(1) 아니오
(2) 예

※ 다음은 담배를 피운 적이 있는 사람만 기입하시오.

$\square$ 담배를 하루에 한 개피 이상 매일 피우기 시작한 것은 몇 살 때부터입니까?
만
살, 혹은 19
년도

현재에도 담배를 피우고 있습니까?

(1) 아니오 $\rightarrow$ 담배를 끊었다면 몇 살 때까지 마지막으로 피우고 끊었습니까?

만_살, 혹은 19 년도

(2) 예 $\rightarrow$ 하루에 평균 몇 개피나 피우십니까? 개피

당신은 일주일에 보통 얼마나 많은 양의 술을 드십니까?

(술 한잔 기준: 맥주 1캔, 와인 1잔, 양주 1잔, 소주 2잔) 잔 (1주일 기준)

$\square$ 지난 1년 동안 당신은 1주일에 며칠을 운동하였습니까? 또한 한 번에 몇 분 정도, 그리고 운동을 한 이유에 대해서도 답해 주기 바랍니다(1번 9번)

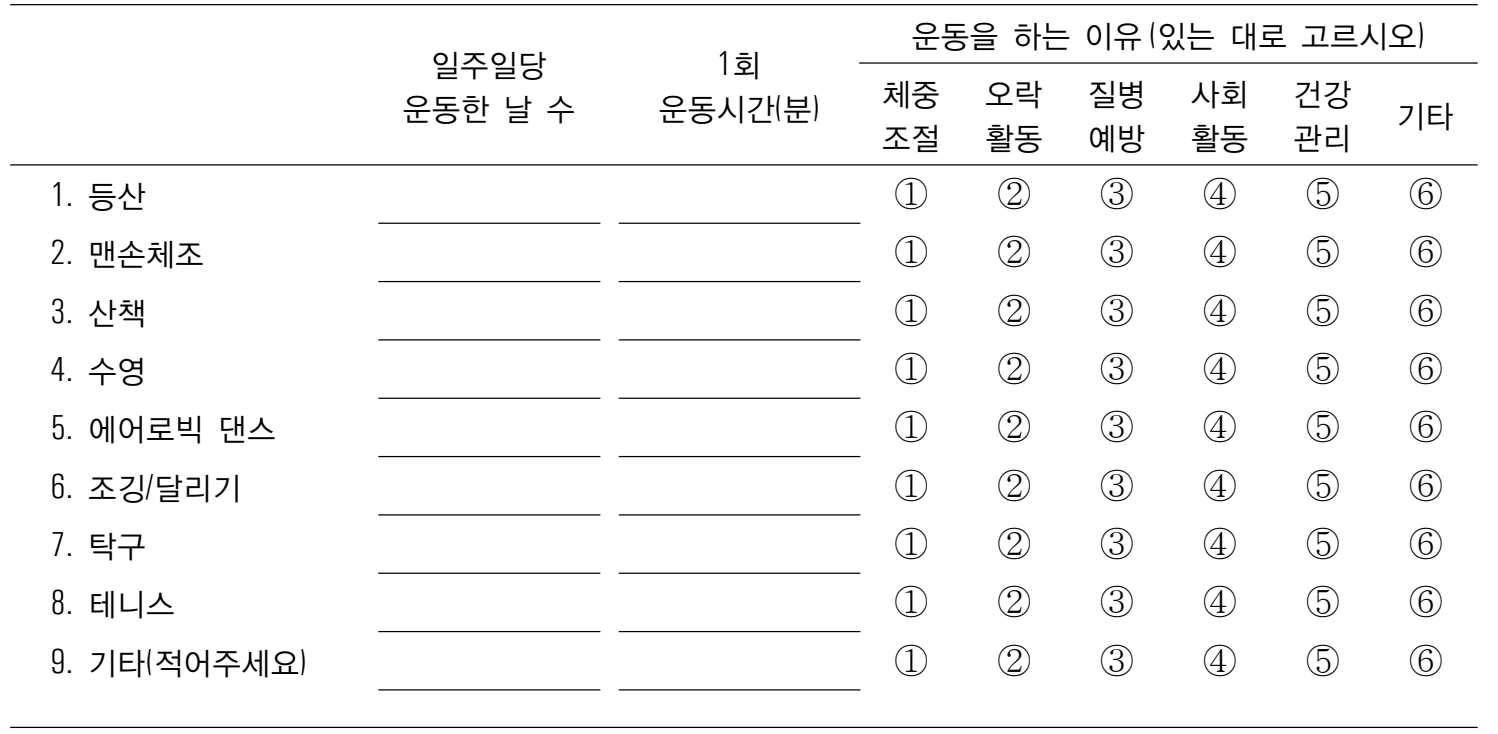


전반적으로 현재 당신의 신체적인 건강에 대해 어떻게 생각합니까?

(1) 건강하다

(2) 병은 없지만 건강한 편은 아니다

(3) 무슨 병이 있는 것 같다

(4) 질병이 있다

$\square$ 당신은 일주일에 얼마나 자주 아침식사를 합니까? 번 (일주일 기준)

당신은 전반적으로 당신의 정신적인 건강에 대해 어떻게 생각하십니까?
(1) 나쁘다
(2) 보통이다
(3) 좋다
(4) 아주 좋다

당신은 하루 밤에 보통 몇 시간 정도 잡니까? 시간 (하루 밤 기준)

당신은 공부 때문에 바쁘다고 느껴본 적이 얼마나 됩니까?
(1) 대부분의 사람들보다 덜하다
(2) 대부분의 사람들과 같다
(3) 대부분의 사람들보다 더 많다

$\square$ 당신은 학교나 집에서 스스로 시간을 정해 놓고 공부하는 편입니까?
(1) 그렇게 하지 않는다
(2) 그렇게 한다
(3) 일주일에 한 번 이상은 그렇게 한다
※ 다음 질문에 답해 주기 바랍니다해당하는 곳에 직접 적거나 $\boldsymbol{v}$ 표시를 하기 바랍니다).
$\square$ 귀하의 학번과 이름을 적어주기 바랍니다: 학번 이름
$\square$ 귀하는 몇 살입니까? 만 살
$\square$ 귀하의 성별은 무엇입니까?
(1) 남
(2) 여
$\square$ 귀하의 종교는 무엇입니까? (1) 없음
(2) 기독교
(3) 천주교
(4) 불교
(5) 기타
$\square$ 현재 귀하의 신장과 체중은? 신장 $\mathrm{cm}$, 체중 $\mathrm{kg}$

